\title{
Research on Interactive Participation among Generation Z Consumers in Simulation Games
}

\section{-- A Case Study of Picturesque Panorama of Jiangnan based on Grounded Theory}

\author{
Wen Zhang \\ School of Journalism and Communication, Huaqiao University, Xiamen, China \\ zw8182@163.com
}

\begin{abstract}
In recent years, the mobile game market has shown remarkable performance, especially the upsurge of simulation games which mainly targeted at Generation Z. This paper takes Picturesque Panorama of Jiangnan, a renowned simulation game in China, as a case study and focuses on the interactive participation of its players. The author conducted in-depth interviews with 15 consumers of this game and comprehensive discussions on their interactive behavior, identity and willingness to participate based on the Grounded Theory, and tries to build a model of influencing factors to explain the relationship between the three and summarizes the characteristics of interactive participation of Generation $Z$ in simulation games: replayable, recordable and concealable.
\end{abstract}

Keywords: Picturesque Panorama of Jiangnan; Generation Z; Interactive Participation; Rooting Theory.

\section{Introduction}

With the opening of a new era of mobile Internet communication, the "meta-universe", the future form of the evolution of the Internet industry, has entered the limelight, and simulation games, the prototype of the "meta-universe", have become a boom. The explosion of simulation games such as Mole's World and Harry Potter verified the scale of Generation Z, a group of "indigenous people of the virtual world", and the broad prospect of the game track for Generation $Z$ was confirmed. However, in recent years, the new regulations of mobile games have raised the threshold and the fierce competition of oligopolies have restricted their continuous operation and iteration. How to correctly examine the interactive participation of consumers has become a problem that simulation games need to solve.

Created by Coconut Island Games, Picturesque Panorama of Jiangnan is a simulation game in ancient style, in which players are transformed into urban designers to return to Jiangnan, an area of the Ming Dynasty, and draw their personal picturesque panorama through planning and management. After the game was released, it quickly became a hit, with over 1 billion microblogging topics read in just one month, and topped the App Store free game list for several days. As is shown in Figure 1, the game consists of four parts of core modules: tasks in Management Module is unlocked one by one along with the main plot, which serves as a guide for newcomers and enhances the immersion of the game; Card Module precisely hits the "addiction psychology" of users (consumers are guided to the product and encouraged to accumulate inputs by giving them variable rewards in their purchases, resulting in spontaneous purchases and circulations); Adventure Module enriches the story background and further enhances players' participation; Social Contact Module maintains the stability of the game in the outreach. At the same time, the game adopts many visual and auditory symbols to convince players to participate in the game by the peripheral route. 


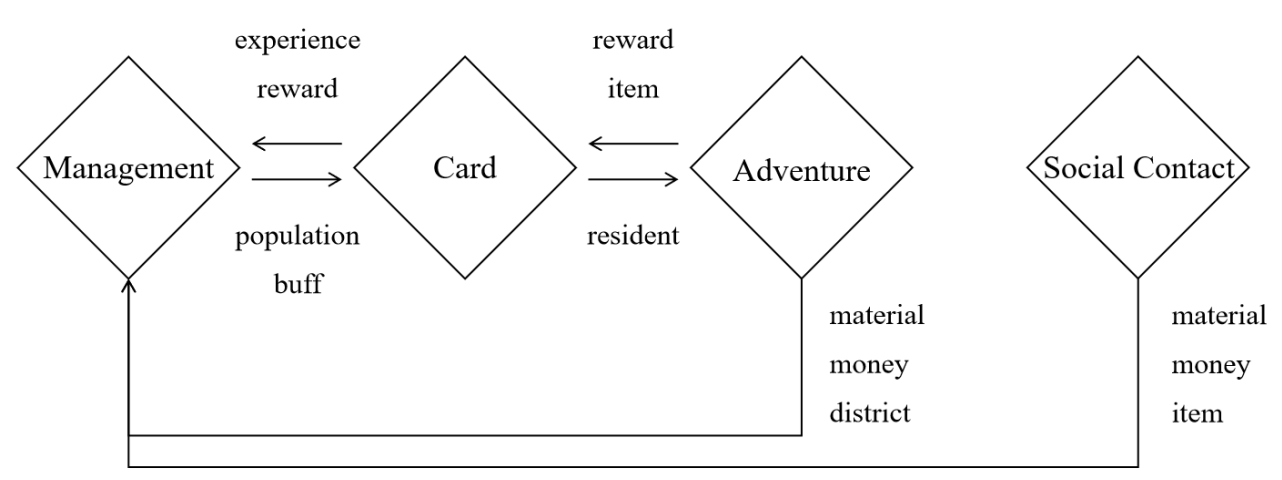

Fig 1. Core modules of Picturesque Panorama of Jiangnan

This study is about "interactive participation" in mobile game context. Pine and Gilmore (1998) divided interactive participation into four aspects: entertainment, learning, aesthetic and recluse experience; Schmidt (2001) divided it into five forms: sensory, emotion, thinking and action and formed the framework of experience economy marketing by this way; Huang Shaohua (2008) summarized that the current research on online behaviors mainly focuses on online environment and interaction relationship; Guan Pingping (2012) argues that players' multi-directional choices and involvements in the game world are reflected in game interaction. Most studies on the two either analyze it simply as a realistic marketing result and discuss the commercial mechanism in it, or make analysis only on the virtual environment and behavioral results and infer the motives of consuming behavior back from the result and influence, ignoring the subjectivity of consumers in game participation.

Based on this, the research questions and analysis ideas explored in this paper are: what factors contribute to the interactive participation of Generation $\mathrm{Z}$ in simulation games, and what mechanisms of action are embedded within these factors.

\section{Study Design and Implementation}

\subsection{Research Methodology}

This study aims to investigate the logic of interactive participation of Generation $\mathrm{Z}$ in simulation games. But at present, it is difficult to conduct quantitative research due to the difficulty of variable quantities and data mining, so the in-depth interview method is used to obtain more information based on observation by conducting semi-structured interviews with objects. Grounded theory is a bottomup approach to build a substantive theory, that is, to find the core concepts reflecting social phenomena on the basis of systematic data collection. The American sociologist Strauss defined a corresponding three-level coding procedure for it: open coding, axial coding and selective coding.

In summary, this study will conduct a research based on in-depth interview data to effectively explore the logic of interactive participation of Generation $\mathrm{Z}$ in simulation games.

\subsection{Research Object}

Online virtual communities are crowded with a large number of mobile game players, who engage in various interactive activities such as exchanging, sharing and discussing on social media according to their respective needs. The author chose two representative groups, Douban group and WeChat group, as the observation environment. In Picturesque Panorama of Jiangnan (Douban group) and Peach Blossom Village (QQ group), the author conducted an in-depth research with the help of participatory observation. Douban group now has 38,674 "Magistrates" (the name for members in Picturesque Panorama of Jiangnan Douban Group). Compared to the Picturesque Panorama of Jiangnan Sina Weibo Super Topics, it has more application requirements, fewer padding and arguing 
posts, higher frequency of post changes and higher rate of like/comment by players. Peach Blossom Village is a QQ group composed of 45 players of Picturesque Panorama of Jiangnan, with an average of about 300 chats per day, involving game strategy layout, mutual assistance, role-playing and other aspects.

This study used a snowball sampling method to find interviewees (shown in Table 1), and a total of 15 semi-structured interviews of an average length of about 45 minutes were conducted with Generation $Z$ groups from different social backgrounds, resulting in more than 60,000 words of primary data.

Table 1. Basic information of interviewees

\begin{tabular}{|c|c|c|c|c|c|}
\hline Model & Gender & Age & Career & $\begin{array}{c}\begin{array}{c}\text { Game Length } \\
\text { (months) }\end{array} \\
\end{array}$ & Total consumption (CNY) \\
\hline A1 & Female & 21 & College Student & 5 & 90 \\
\hline $\mathrm{A} 2$ & Female & 17 & High School Student & 6 & 500 \\
\hline A3 & Male & 24 & System Engineer & 6 & 30 \\
\hline A4 & Female & 22 & College Student & 3 & 18 \\
\hline A5 & Female & 20 & College Student & 2 & 150 \\
\hline A6 & Female & 21 & College Student & 5 & 30 \\
\hline A7 & Female & 19 & College Student & 4 & 50 \\
\hline $\mathrm{A} 8$ & Female & 23 & Sales clerk & 7 & 300 \\
\hline A9 & Female & 25 & Choreographer & 10 & 200 \\
\hline A10 & Male & 18 & High School Student & 12 & 30 \\
\hline A11 & Female & 23 & Operating Officer & 4 & 45 \\
\hline $\mathrm{A} 12$ & Male & 20 & College Student & 5 & 30 \\
\hline A13 & Female & 16 & High School Student & 3 & 30 \\
\hline A14 & Male & 23 & Graduate Student & 14 & 100 \\
\hline A 15 & Female & 19 & College Student & 15 & 174 \\
\hline
\end{tabular}

\subsection{Code Processing}

\subsubsection{Open Coding}

In this study, 54 primary concepts are obtained from the primary source, and 14 initial categories are refined. To save space, only the first 6 initial categories are listed. Parts of the open coding results are shown in Table 2.

Table 2. Concepts and initial scope of open coding formation

\begin{tabular}{|c|c|c|c|c|}
\hline \multicolumn{2}{|r|}{ Initial Scope } & \multirow{2}{*}{$\begin{array}{c}\text { Initial Concept } \\
\text { Scenario } \\
\text { reproduction }\end{array}$} & \multicolumn{2}{|r|}{ Example of objects and original statements } \\
\hline \multirow{5}{*}{$\mathrm{X} 1$} & \multirow{5}{*}{$\begin{array}{l}\text { Sensory } \\
\text { Immersion }\end{array}$} & & A3 & $\begin{array}{l}\text { "......is reflected from selecting and cutting the straw to } \\
\text { steaming the grass and putting it in the sun ......" }\end{array}$ \\
\hline & & Background sound & A4 & ".....like the sound of a bazaar......" \\
\hline & & $\begin{array}{l}\text { Character } \\
\text { appearance }\end{array}$ & A7 & $\begin{array}{l}\text { "......the characters in the cards are also beautifully } \\
\text { drawn ......" }\end{array}$ \\
\hline & & Game style & A12 & $\begin{array}{c}\text { ".....painting style is exquisite, is the traditional cultural } \\
\text { style ....." }\end{array}$ \\
\hline & & $\begin{array}{l}\text { Historical details } \\
\text { restoration }\end{array}$ & A13 & $\begin{array}{l}\text { "......for example, the buildings complex around the } \\
\text { memorial hall are all from Duleyuantu painted by a well- } \\
\text { known artist Qiu Ying ......" }\end{array}$ \\
\hline \multirow[t]{2}{*}{$\mathrm{X} 2$} & \multirow[t]{2}{*}{ Persona Show } & $\begin{array}{l}\text { Assume } \\
\text { responsibility }\end{array}$ & $\mathrm{A} 2$ & $\begin{array}{l}\text { "......as the governor, similar to the image of a modern } \\
\text { mayor, I have the responsibility to build up my city and } \\
\text { my land ......" }\end{array}$ \\
\hline & & $\begin{array}{l}\text { Participate in } \\
\text { activities }\end{array}$ & A3 & $\begin{array}{c}\text { "......I disguised as a miller to choose materials, as if I } \\
\text { made my own rice paper ......" }\end{array}$ \\
\hline
\end{tabular}




\begin{tabular}{|c|c|c|c|c|}
\hline & & Review journeys & A9 & $\begin{array}{c}\text { "......clock in Weibo's super topics every day, and share } \\
\text { some fragmented screenshots ...... look back at my past } \\
\text { thirty days ......" }\end{array}$ \\
\hline & & Conduct role-play & A15 & $\begin{array}{l}\text { "......at one time I played a role as Tang Xianzu, and his } \\
\text { lover Duliniang is also the role I fond of......" }\end{array}$ \\
\hline \multirow{2}{*}{$\mathrm{X} 3$} & \multirow{2}{*}{$\begin{array}{l}\text { Narrative } \\
\text { Mechanism }\end{array}$} & Personal Narrative & A4 & $\begin{array}{c}\text { "......can hear some chit-chats from the villagers, } \\
\text { sometimes gossip ......" }\end{array}$ \\
\hline & & $\begin{array}{l}\text { Grand linear } \\
\text { narrative }\end{array}$ & A8 & $\begin{array}{l}\text { "......most of them are historically recorded characters with } \\
\text { stories known to all ......" }\end{array}$ \\
\hline \multirow{3}{*}{$\mathrm{X} 4$} & \multirow{3}{*}{$\begin{array}{l}\text { Learning } \\
\text { Behavior }\end{array}$} & Knowledge & A2 & $\begin{array}{l}\text { "......relying on Chinese traditional cultural resources, it } \\
\text { encourages more young people to understand Chinese } \\
\text { history ......" }\end{array}$ \\
\hline & & Capabilities & A6 & $\begin{array}{l}\text { "......will have architectural professional thinking when } \\
\text { playing the game, such as the road can not be constructed } \\
\text { completely against the wall ......" }\end{array}$ \\
\hline & & Values & A10 & $\begin{array}{c}\text { "......from the perspective of traditional culture .......a great } \\
\text { way to enhance our national identity and cultural } \\
\text { confidence ......" }\end{array}$ \\
\hline \multirow{4}{*}{$\mathrm{X} 5$} & \multirow{4}{*}{ Re-creation } & Browse & A6 & $\begin{array}{c}\text { ".....I will browse Tik Tok concerning the game, such as } \\
\text { those amazing drawings ......" }\end{array}$ \\
\hline & & Use & A14 & $\begin{array}{l}\text { "......is about the card draw, you have to get all the } \\
\text { residents out of your house first ......" }\end{array}$ \\
\hline & & Design & A1 & $\begin{array}{l}\text { "......I spent a lot of money to buy the eight fairy lights to } \\
\text { make the night scene, arranging my characters on the } \\
\text { bridge to look at the moon and to see the lotus ......" }\end{array}$ \\
\hline & & Interaction & A5 & $\begin{array}{c}\text { "......hosts the City Planning Contest .......sets scoring } \\
\text { guidelines......" }\end{array}$ \\
\hline \multirow{3}{*}{ X6 } & \multirow{3}{*}{$\begin{array}{l}\text { Landscape } \\
\text { Construction }\end{array}$} & $\begin{array}{c}\text { Copy } \\
\text { other players }\end{array}$ & A8 & $\begin{array}{l}\text { "......feel not creative enough, so my layout is all copied } \\
\text { from those masterpieces by others ......" }\end{array}$ \\
\hline & & $\begin{array}{l}\text { Revive } \\
\text { history }\end{array}$ & A9 & $\begin{array}{l}\text { "......build the scenery described in Dream of the Red } \\
\text { Chamber ......put an identical one in my city ......" }\end{array}$ \\
\hline & & $\begin{array}{c}\text { Base on } \\
\text { Personal preference }\end{array}$ & A10 & $\begin{array}{c}\text { "......have a kind of idealized model on my own to give it } \\
\text { a layout ......" }\end{array}$ \\
\hline
\end{tabular}

Table 3. Results of axies coding

\begin{tabular}{|c|c|c|c|c|c|}
\hline \multicolumn{2}{|r|}{ Main Category } & \multicolumn{2}{|r|}{ Sub-category } & \multicolumn{2}{|r|}{ Initial Scope } \\
\hline \multirow{8}{*}{$\mathrm{Z} 1$} & \multirow{8}{*}{ Interactive Behavior } & \multirow{2}{*}{ Y1 } & \multirow{2}{*}{$\begin{array}{l}\text { Multi-faceted Persona } \\
\text { from Subsuming to Resetting }\end{array}$} & $\mathrm{X} 1$ & Sensory Immersion \\
\hline & & & & $\mathrm{X} 2$ & Persona Show \\
\hline & & & & $\mathrm{X} 3$ & Narrative Mechanism \\
\hline & & $\mathrm{Y} 2$ & Curatorial Consumption & $\mathrm{X} 4$ & Learning Behavior \\
\hline & & & 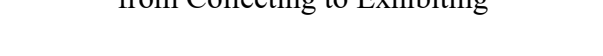 & $\mathrm{X} 5$ & Re-creation \\
\hline & & & & $\mathrm{X} 6$ & Landscape Construction \\
\hline & & & Linked Social Relationships & $\mathrm{X} 7$ & Social Burnout \\
\hline & & $1 J$ & from Presence to Departure & $\mathrm{X} 8$ & Media Burnout \\
\hline \multirow{3}{*}{$\mathrm{Z} 2$} & \multirow{3}{*}{ Identity } & \multirow{2}{*}{ Y4 } & \multirow{2}{*}{$\begin{array}{l}\text { Behavioral Identity of Players Interacting with } \\
\text { the Game }\end{array}$} & $\mathrm{X} 9$ & Embodiment Identity \\
\hline & & & & $\mathrm{X} 10$ & Game Identity \\
\hline & & Y5 & $\begin{array}{c}\text { Psychological Identity of Players Interacting } \\
\text { with People }\end{array}$ & $\mathrm{X} 11$ & Group Identity \\
\hline \multirow{3}{*}{$\mathrm{Z} 3$} & \multirow{3}{*}{$\begin{array}{l}\text { Willingness to } \\
\text { Participate }\end{array}$} & \multirow{3}{*}{ Y6 } & \multirow{3}{*}{$\begin{array}{l}\text { Willingness to } \\
\text { engage in Simulation Games }\end{array}$} & $\mathrm{X} 12$ & Continious Engagement \\
\hline & & & & $\mathrm{X} 13$ & Recommending Intention \\
\hline & & & & X14 & Price Tolerance \\
\hline
\end{tabular}




\subsubsection{Axies Coding}

54 descriptions from the open coding are categorized, and 6 categories are identified. By thinking deeply about the relationship between the thematic categories, this study gradually refines into more meaningful and conceptualized main categories: interaction behavior, identity, and willingness to participate. The coding results are shown in the Table 3.

\subsubsection{Selective Coding}

Finally, a new substantive theoretical framework (shown in Figure 2) is developed by forming a core coding group of "factors influencing the interactive participation of Generation $\mathrm{Z}$ consumers in simulation games" through selective coding.

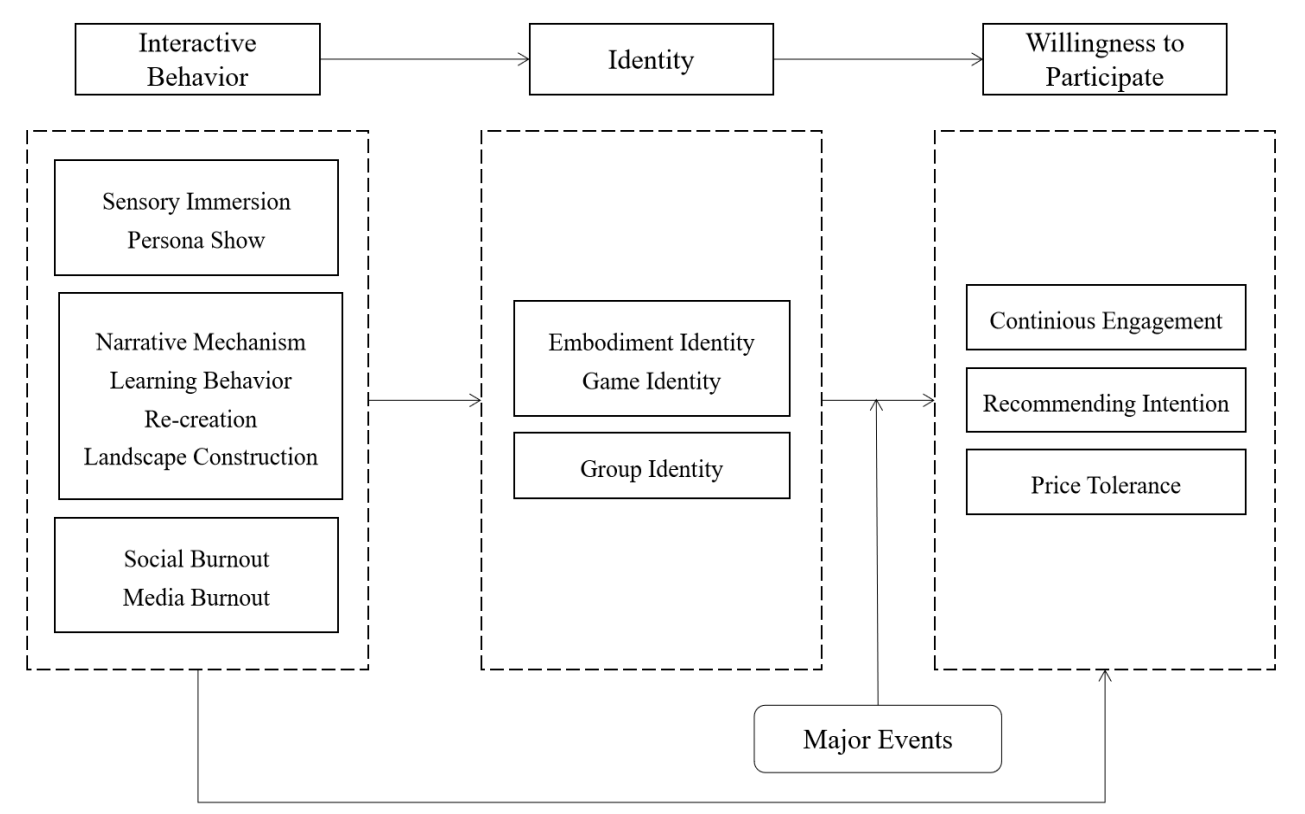

Fig 2. Framework of interactive participation of Generation $\mathrm{Z}$ in simulation games

\section{Research Analysis and Findings}

\subsection{Consuming Behaviors in Picturesque Panorama of Jiangnan}

\subsubsection{Self-spectacularization Shaped by Media Availability}

"Our ability to present ourselves online - whether it is real, fantasy or constructed - is limited and supported by communication tools and our strategic image management skills [1]." The platform shown by the game Picturesque Panorama of Jiangnan is "available" (according to American communication scientist Schrock, "communication availability" refers to the interaction between users' subjective sense of usefulness and the objective nature of the technology that changes communication practices or habits) in this process. The interconnectedness and interplay of many elements of the game setting demonstrate the "social availability" of the basic indicator framework of "media availability", which is "addressable, communicative, coordinated, and connectable ".

According to Freud, "When people's desire for the original object cannot be satisfied due to obstruction, they will look for a substitute close to the original one so that their need can be satisfied, thus eliminating the tension and anxiety [2]." In the game Picturesque Panorama of Jiangnan, players are invited to play the role of Lord Yan, the governor of Jiangnan for the restoration of this region. In the game, this kind of role-playing satisfies some players' desires for control and design as well as consuming-derived psychological expectations. In addition to the coordinating role of the "governor", Picturesque Panorama of Jiangnan also offers the roles of ordinary residents for players to act in, 
which is "low-involvement". This is because Jiangnan is exactly the living environment for residents and dwellers are everywhere to be found. Like water permeating, participation of role play in such characters is more accessible to consumers. In general, Picturesque Panorama of Jiangnan helps consumers to avoid the "malfunction" of frontstage performances and even the "inside story" of backstage ones, and to reshape, reorganize and rearrange the logic and flow of the play through different character experiences.

In Goffman's view, "individuals act in a completely planned way, presenting themselves in a given way [3]." They conspire with social media to use this equipment in a socially favorable way, allowing their daily performances to be embellished and highlighted. With the development of online communication, its universality and complexity have raised the difficulty of persona performance, and one single media stage may no longer be able to adapt to this change, so that Generation $\mathrm{Z}$ will perform their personas on two or more media. Take Sina Weibo Super Topics as an example, its unique mechanism of daily "clocking in" provides technical support for the psychological mechanism of "daily reminiscence" of consumers, and is also an ideal operation for players to ensure the stability and continuity of their personas. In the process, the author met two interviewees who had clocked in the Super Topics for 8 months and 1 year relatively. Interviewee A9 believed that clocking in belongs to the paradigm of "individual retrospection" for a certain period. Interviewee A11, on the other hand, viewed the individual act of clocking in as a collective act of hypertextuality, and regarded it as belongingness. Regardless of the paradigm of "retrospection", it reflects the individual presentation in games and the idealized social performance.

\subsubsection{Curatorial Consumption Drived by Collectomania}

In Picturesque Panorama of Jiangnan, the worldview is structured as a reference and transformation of existing legends, with myths in the context of the Ming Dynasty, and the narrative paragraphs are distributed in dots and linked into a complete text through players' interaction. In the interviews, the words "worldview" and "story line" were proactively mentioned and approved by more than half of the players. Compared with the grand narrative of the main line, the personal narrative makes the player's choices become the decisive factor of the whole story. Picturesque Panorama of Jiangnan is a branch of simulation games, the core of which lies in "free creation". The biggest difference between it and other types of games is that it does not propose a clear goal or mission for players, but provides players with an interactive, open virtual world and related internal rules [4]. Players can have an adventure as if they actually were heroes when building or acting in the game, and the process of the player's town being constructed is making narratives.

Restricted by the weak communication of the game Picturesque Panorama of Jiangnan, consumers usually choose to publicly participate in some game-related derivative activities through other social media or platforms to seek recognition in the circle. Consumers' involvement in the game also shows a deep change from browsing, using, designing to interacting. The shallowest level of consumer participation in the game stays at browsing, among which viewing the fanfictions and fanarts is the most representative. At the primary stage of participation, there is another mode called strategy output. During the interview, the author met an aficionado, a blogger with 10,000 followers, and he said that his output of strategy is no longer the traditional linear interaction mode. The comments and likes from players, the forwarding from the game's official blog, and the discussion from the social media are all the driving forces why he insisted on updating every week. It was the source of confidence and motivation for him. On top of browsing and using the game, some consumers who are exposed to the game will be eager to participate in the game at a deeper level that they will often enjoy the freedom and liberty to "make decorations" both in and out of the game, thus forming a unified and coordinated "theater" that sustains their own emotions or identity with the game. Other results show that more players still claim they will create or build things according to their personal preferences, and they regard landscape building as a "mysterious state" in which they can complete the presentation or elimination of themselves in parallel dimensions, and the virtual nature of the game can also create a relative sense of security and freedom. 


\subsubsection{Ruralism Revival Derived from Two Types of Burnouts}

"The growing number of connections extends social relationships among people, while simultaneously transferring more relational burdens and social pressures to individuals [5]." The connection is thus devalued, and the corresponding costs and consequences call for new choices to be made in order to avoid them. Under the high pressure of modern life, people exhibit their daily lives in the foreground in order to show their ideal persona, and Merovitz's Media Context Theory further points out that the emergence of media makes the backstage become the foreground as well, and in the long run, the masses are prone to burnout and expect to remove their external pretensions. "Absence makes the heart grow fonder", as interviewee A3 says, it is under the virtual nature of the network that the authenticity of personality is highlighted, and video game socialization facilitates interaction between players and players in a more real and sincere manner.

The complexity of social interaction leads to an increase in worries and a decrease in interest in refusing to have compulsory social interaction, and the resulting social anxiety will eventually turn into social burnout. The light social function of Picturesque Panorama of Jiangnan provides players with a "moderate disconnection" or "anti-connection" mindset, which has become a blessing to many "social phobics" or those who want to "reduce the social burden". Disappointment, fatigue, and inevitability of the experience exacerbate the quantitative overload of user resistance, easily shifting people from "constant presence" to "desire to leave". The simulation games, whose approach is cutting out and finding another place, can give players the possibility to "build a mental world that can save them from their daily worries" again and again. The platform-dependent nature of social connections has also led to a gradual shift in burnout and resistance toward the social medium itself. The combat function of massive multiplayer online games and some mobile games emphasizes "cooperation", in which communication with strangers is inevitable. As the frequency and density of consumers' media touch and connection increase, the cost of management and participation becomes higher, and users' media burnout is further intensified. When the role video games play in leisure time turns from "helping" into "leading", it brings "the colonization of daily life by cyberspace", and once such bond is loosened, it will feel like stepping into a "primitive world". Picturesque Panorama of Jiangnan is a simple mechanism to rescue players from the disorientation of reality and virtual spacetime, while satisfying the needs of consumers. In a way, it is more like "farming", using the "slow" pace of the game to improve the audience's perception and make the distance between the game and the players' mind closer.

\subsection{Consuming Identity in Picturesque Panorama of Jiangnan}

\subsubsection{The Romantic Nostalgia of "Cyber Part-time Farmers"}

Game identity refers to consumers' identification with the game's mechanics or settings, which is one of the levels of players' interaction with the game and is easily accessible. Since some people are dissatisfied with the real society and are losing confidence in their self-identity and self-development, they are constantly trying to find an outlet in the way of self-expression and catharsis. The inability of reality to satisfy people's increasing physical and spiritual needs also leads people to fantasize about themselves on the path of self-identity.

But affection for the "farming game" is not the same as affection for "farming". In the world created by the game, the farming life is actually filtered, and a famous poem in China can be quoted to describe this illusion of pastoral peace: "Work once the sun glitters on the trees and pastures, and go back to home as the moon shines." This idyllic life has already been transformed into games on screen. Raymond Williams pointed out in The Country and the City that the history of literary works has been full of "over-glorification and imagination" of idyllic life, and that the slow pace and richness of the world reflect our longing for a leisurely and idyllic life, as well as our re-examination of complex human relationships [6]. The explosion of Picturesque Panorama of Jiangnan is actually an opportunity of the times. It is like a timely rain, allowing the feelings of interaction with people, the enthusiasm of serious life and the desire for the outside world in the "pre-epidemic era" to sprout again. 


\subsection{2 "Virtual Group Building" in the Interactive Ritual Chain}

Based on Interactive Ritual Chain Theory by Collins, the game participation of Picturesque Panorama of Jiangnan can be regarded as a spontaneous "virtual group building" of players. All the virtual players present in the game form a collection, and through long-term ritual participation such as clocking in and completing tasks, a certain emotional energy bursts out, constituting an interactive ritual chain, at which time the sense of participation in the game comes from "routine actions or practices". Picturesque Panorama of Jiangnan organizes offline derivative activities to leave deep impressions on online players, and this kind of activity usually has a low threshold for participation, thus players, whether in the circle or not, can participate proactively or passively, which also helps to attract more groups into this circle. The interview results show that many consumers' pleasures when participating in the game comes from the "moment" they press the "buy" button, and through the momentary consumption to obtain a short emotional stimulation. The game groups also have a "barrier" that excludes outsiders, and players with strong subcultural capital are embraced as key opinion leaders and can have more power. A united group is formed after the collective excitement of a massive multiplayer-mission or media spectacle, and individual emotions are released and accumulated. A particular example is the "Kongming Lantern Display". As a collective cultural symbol of group identity, it expresses the beautiful vision inside and outside the game.

It is highlighted that the aforementioned model shows that "major events" play a mediating role in the path from "identity" to "willingness to participate" for Generation Z consumers. In the new media context of the Internet, the boundaries of personal identity construction and other behaviors are gradually dissolving, and the "banal nationalism" (proposed by Billig, it includes everyday political discourse, nation-state symbols present in various contexts, special rhetoric and metaphors, and mass media constructs from every aspects of daily life) has made it possible to connect the grand narrative of the nation-state with the trivial life of individuals, which to a certain extent also creates the possibility of interactive rituals for players. During the process, the author found that the incident of Yue Fei (a national hero in China, was given the nickname "idle man" in Picturesque Panorama of Jiangnan national, which was later warned by CCTV and asked to be rectified) in the game was the reason why many people uninstalled or quitted the game, and even for players who were previously enthusiastic about the game, this could be a prominent reason for their attitude change. Through this "forgotten performance", the people concerned spontaneously censor the game text. This time their action logic is no longer "boycotting all video games" or "kneeling down for games", but a continuous negotiation and choice based on different value trade-offs.

\section{Research Conclusions}

\subsection{Replayable: Building a New Stage to Carry a Multi-faceted Persona}

Consumers build a brand-new masquerade stage for themselves in the simulation game, and present different personas and stories on different stages according to the written plot of the scripts and the characteristics and reactions of the audience, so that the self-scripted and self-directed landscaping is shaped, that is, on the basis of ensuring that the stages do not contradict each other, the inherent nature of the persona is improved through collaboration, so that they can make joint efforts to perform the show with appearances varying.

\subsection{Recordable: Building Parallel Dimensions to Satisfy the Desire to Collect}

Simulation games are a parallel dimension for consumers, and players can also satisfy their desire by curating through the collection of materials, cards or characters in the game. "Free creation" can greatly liberate the creativity and imagination of consumers. As the main subfield, the game helps users to be in a specific "mysterious" state, through some "metaphysical" luck or simply recharging, consumers can grasp the power or resources that are difficult to possess in reality. Such a combination 
of certainty and randomness adds to the freedom of active expression of consumers' emotions and behaviors, and catalyzes the feasibility of personal attribute agenda setting within the user's control.

\subsection{Concealable: Retreating to a Comfort Zone to Relieve Burnouts}

Compared to the fast pace of the real world, the simulation game seems to put the players into the comfort zone, allowing consumers to experience "the slow pace", although it is not possible to permanently "escape from a real world" like a paradise, but at least players can stay for a while for release. This is an "anti-speed" emotional experience, and is somehow more reliable to resonate with consumers. Under the burnouts of both social and media, simulation games play a similar role as a "hometown", where consumers can get rid of the previous trap and the "kidnapping" of the usual game, and then get a rest. This kind of self-adjustment approach is actually in line with the concept of "anti-connection".

The simulation game has built a virtual space that is replay able, recordable and concealable for the interactive participation of the Generation $\mathrm{Z}$ consumers, reflecting the further extension of the users' understanding and domestication of the medium, and reflecting the mutual participation and resonance of the relationship between people and technology.

\section{Acknowledgments}

I would like to express my gratitude to all those who gave me the opportunity to complete this thesis.

First of all, I would like to give my sincere gratitude to Miss Xu Changhao, my tutor who, with extraordinary patience and consistent encouragement, gave me great help by providing me with necessary materials, advice of great value and inspiration for new ideas.

Second, I am very obliged to Mr. Liu Han, Mrs. Ma Li and Mrs. Li Jing. It is these distinguished teachers who gave me the opportunity to step into the academic world.

Then I am pleased to acknowledge my friend $\mathrm{Fu}$ Xinyi for her invaluable assistance throughout the preparation of the original manuscript.

Finally, in particular, I would like to express my gratitude to my parents for their support. They provided many learning materials for me and they are of great help for me to finish the essay successfully.

\section{References}

[1] Ren Wen. How does social media affect our desire for expression? --An exploration based on communication visibility research. Research on Transmission Competence. Vol. 4 (2020) No. 8, p. 165166.

[2] Freud. Creative Writers and Day-Dreaming. Collected Papers. Vol. 4 (1927).

[3] Goffman. The presentation on self in everyday life. Peking University Press, 2008, p. 30.

[4] Li Xinwei: Interactive narrative research based on video game cases (Master Degree, Southwestern University, China 2021). p. 15.

[5] Sun Wenzheng. Self-tracking, datafication and sociality: time management in the mobile Internet era. Modern Communication (Journal of Communication University of China). Vol. 43 (2021) No. 7, p. 158163.

[6] Information on: https://baijiahao.baidu.com/s?id=1663643815890892963. 